\title{
Numerical and Experimental Investigations of Lift and Drag Performances of NACA 0015 Wind Turbine Airfoil
}

\author{
İzzet Şahin and Adem Acir
}

\begin{abstract}
In the present work, we studied numerical and experimentally analysis lift and drag performances of NACA 0015 airfoil at different attack angle at low Reynolds numbers (Re) by measuring the forces every two degrees from $0^{\circ}$ to $20^{\circ}$. The experiment test was conducted in low speed wind tunnel, and the numerical analysis was performed using CFD program which was FLUENT. The results obtained from experiment and numerical were compared. In this study, stall angle depended on turbulent occurred behind airfoil was determined. As result, effect of the stall angle of airfoil performance was investigated.
\end{abstract}

Index Terms-Angle of attack, CFD, NACA 0015, wind tunnel.

\section{INTRODUCTION}

Energy is very important for human life. As it is well-known, energy is produced by fossil fuels, but fossil fuels have two problems. First, its resources are very limited. Second, they lead to environmental pollution. For this reason, renewable energy as alternative resource is emerged necessarily. One of the renewable energy is wind energy. Wind turbines use wind energy to transform into electrical energy but wind turbines efficiency is not good. Because of that, a number of scientists are investigated over wind turbines and wind turbines parameters. One of the most important parameter of wind turbines is wing because wind hits to the wings and energy of wind is transformed into the mechanical energy by wings. In the literature, wings profiles are called as airfoils. Airfoil profile is the important parameter for wing design because wing efficiency increases depending on airfoil profile, so there are a lot of studies over the airfoil profile as numerical and experimental in the literature.

Experimental investigations are very important due to accuracy. However, those take much time and economic and whenever we want to change a parameter about our study, it is very difficult because of time and economic. Fortunately, investigators can study very fast and easily thanks to computational fluid dynamics (CFD) programs. These programs can give as correct results as experimental methods. Also, CFD programs can be contributed as regards time and faster according to experimental methods.

NACA airfoil types were investigated in the literature. Generally, a lot of investigators studied lift and drag performances of NACA airfoil. Bhat et al., studied oscillating of NACA 0012 airfoils at around stall angle at low Reynolds number [1]. Benard et al., have investigated on the

Manuscript received March 20, 2014; revised August 1, 2014

İzzet Şahin is with Gazi University, Faculty of Technology, Department of Energy Systems Engineering, 06500 Teknikokullar/Ankara, Turkey (e-mail: izzetsahin@gazi.edu.tr). enhancement of the air foil performance by using a plasma actuator in steady and unsteady models [2]. Yao et al., have computed aerodynamic performance analysis of NACA0018 wind turbine airfoil by using numerical simulation method. The authors investigated lift, drag performances and surface pressure by changing attack angle using different turbulence model [3]. Lianbing et al. have investigated performance of wind turbine NACA0012 airfoil using FLUENT programs Spalart Allmaras turbulence model to numerical solutions was used by Lianbing et al. of airfoil at $3 \times 10^{6}$ Reynolds number for lift and drag performance and stall angle [4]. Villalpando et al. studied over NACA 63-415 airfoil profile. They used different turbulence model in FLUENT and they saw that SA (Spalart Allmaras) model was better than others models. Also, they investigated aerodynamics of airfoil at low and high angles of attack [5]. Ravi et al. studied over NACA4412 airfoil profile at $3 \times 10^{6}$ Reynolds numbers. The authors investigated transition from laminar flow to turbulence flow by using two different numerical models which were k-epsilon and Spalart Allmaras. Numerical results were compared with experimental results. They indicated two numerical models gave similar results at high Reynolds number [6]. Troolin et al., investigated Gurney flap effect on NACA 0015 airfoil. Initially Daniel Gurney used this flap design on race car so this flap structure known Gurney flap [7]. Troolin et al., added Gurney flap with NACA 0015 airfoil and they numerically investigated performance of this new design. They saw that lift coefficient increased but drag coefficient was not change so this design was useful [7]. Siauw et al., studied on transient dynamics of the flow around the NACA 0015 airfoil by using fluid vortex generator. They experimentally investigated flow separation on NACA 0015 airfoil at $1 \times 10^{6}$ Reynolds number [8]. Srinivosan et al., studied on evaluation of turbulence models for unsteady flows of an oscillating airfoil. They studied on NACA 0015 airfoil by using five different turbulence model. They saw that Spalart Allmaras turbulence model had good agreement with experimental results for lift, drag and moment coefficient [9].

In the present work, the lift and drag performances of NACA 0015 wind turbine airfoil were investigated as numerical and experimentally. Also, different turbulence models were performed. Obtained numerical results were compared with experimental results.

\section{EXPERIMENTAL SET UP}

The measurements have been conducted in an open wind tunnel at the University of Gazi, Faculty of Technology. This tunnel test section long is about $0.4 \mathrm{~m}$ long and flow crosssection is approximately $0.3 \mathrm{~m} \times 0.3 \mathrm{~m}$, interval of wind velocity is from 3.1 to $28 \mathrm{~m} / \mathrm{s}$. Fig. 1-a and 1-c. The airfoil 
used in the present study is an academic NACA 0015 profile as shown in Fig. 1-b. (chord length, c, of $100 \mathrm{~mm}$ and spanwise length, s, of $100 \mathrm{~mm}$ ). Stationary end plates are kept on the two sides of the airfoil, with a small gap of about $1 \mathrm{~mm}$, to help maintain two dimensionality of the flow. The experiments has been conducted at $10 \mathrm{~m} / \mathrm{s}$ wind velocity $(\mathrm{V})$ in tunnel which is corresponding to 68490 Reynolds number (Re).

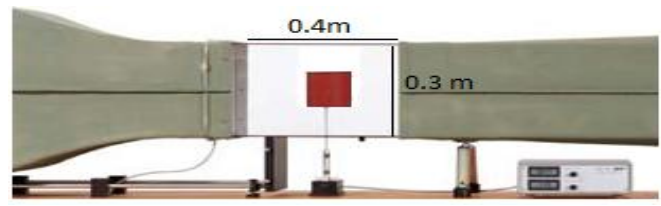

Fig. 1-a. Wind tunnel test area.

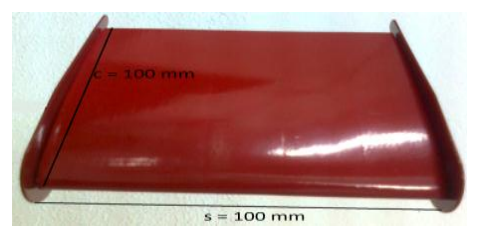

Fig. 1-b. Airfoil details.

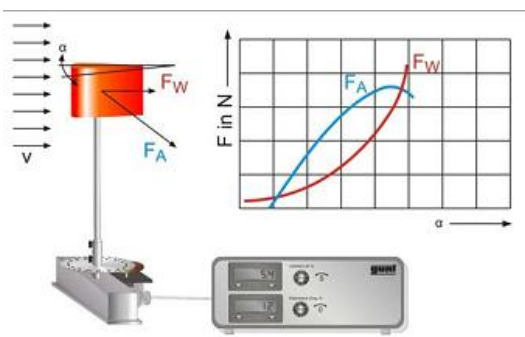

Fig. 1-c. Wind tunnel test mechanism

The airfoil is forced stationary wind velocity to learn lift and drag coefficient, the airfoil profile is attached to electronic two- component coefficient transducer. The values for drag and lift are displayed digitally on the measurement amplifier. (see Fig. 2) The angular position of the airfoil (angel of attack at air foil) in the flow is set by means of a graduated dial.

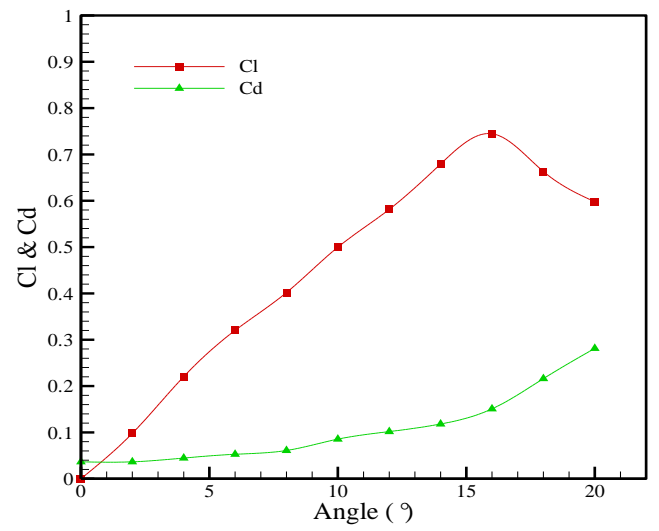

Fig. 2. Lift and drag coefficients at experimental result.

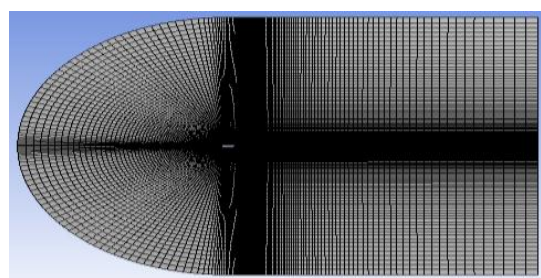

Fig. 3-a. Structure of $\mathrm{C}$ mesh using numerical analysis

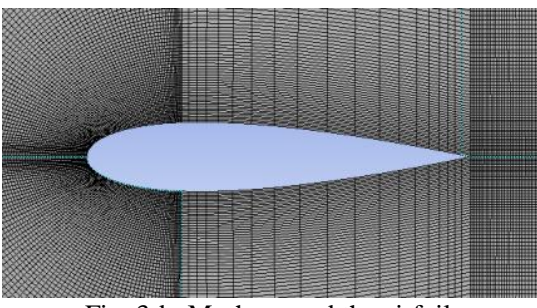

Fig. 3-b. Mesh around the airfoil.

\section{RESULTS AND DISCUSSIONS}

In this study, experimental and numerical analyses were performed. The experiments were conducted at $10 \mathrm{~m} / \mathrm{s}$ wind velocity $(\mathrm{V})$. Lift and drag coefficient of NACA 0015 airfoil at different attack angle between $0^{\circ}$ and $20^{\circ}$ were measurement. Also, the lift and drag coefficient were obtained as numerical with FLUENT programs for the same conditions. In numerical analysis $\mathrm{C}$ mesh used as shown in Fig. 3-a and Fig. 3-b. The top bottom and left boundaries were placed at a distance of 10 chords from airfoil whereas the right boundary was placed at 20 cords. A mesh independence study was performed to verify that the solution would not change subsequent additional refinements and 33600 grids number suitable for our model.

Airfoils have various shape and sizes. Therefore, non-dimensional coefficients (lift and drag coefficients) were taken into consideration to evaluate the advantages and disadvantages of airfoils. The non-dimensional coefficients for two dimensions solution were given as below:

Lift coefficient:

$$
C_{l}=\frac{2 L}{\rho V^{2} c}
$$

Drag coefficient:

$$
C_{d}=\frac{2 D}{\rho V^{2} c}
$$

where $L$ and $D$ are lift and drag force respectively, $C_{l}$ and $C_{d}$ are lift and drag coefficient of airfoil respectively, $c$ is airfoil cord length, $V$ is velocity of wind, $\rho$ is density of air.

The lift and drag coefficient at wind tunnel test for NACA 0015 airfoil were measured as experimentally. The maximum lift and drag coefficient were found as 0.75 and 0.15 for $16^{\circ}$ attack angle. The lift and drag coefficient was primarily effected by attack angle as regards both increasing and decreasing. If attack angle increased, lift and drag coefficient could increase until a certain angle. After the certain angle, the lift coefficient was decreasing whereas; and drag coefficient was increased. This situation was called as stall angle. The stall angle caused transition from laminar to turbulence flow. Also, the lift and drag coefficient were computed with CFD analysis which was used Spalart Allmaras and K-epsilon. As shown in Fig. 4, the Spalart Allmaras, K-epsilon and experimental results were compared. Two methods were compared with experimental results. Spalart Allmaras numerical solution method results have better than K-epsilon. Spalart Allmaras method showed 
similarity experimental results as illustrated in Fig. 4-a and 4-b. Also, the lift and drag coefficient was given in Fig. 6. The best results for lift and drag coefficient were obtained $16^{\circ}$ attack angle. In addition, the best performance $\left(C_{I} / C_{d}\right)$ of NACA 0015 was investigated as shown in Fig. 5. Evaluating $C_{I} / C_{d}$, the best performance was obtained about $8^{\circ}$. There were minor level differences between CFD and experimental results because of measurement error.

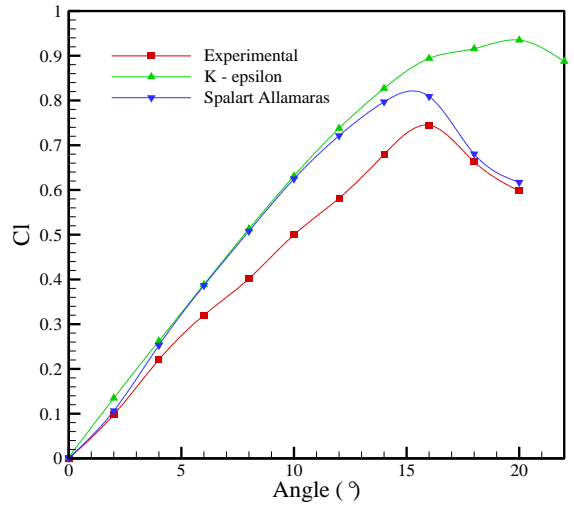

a) lift coefficient

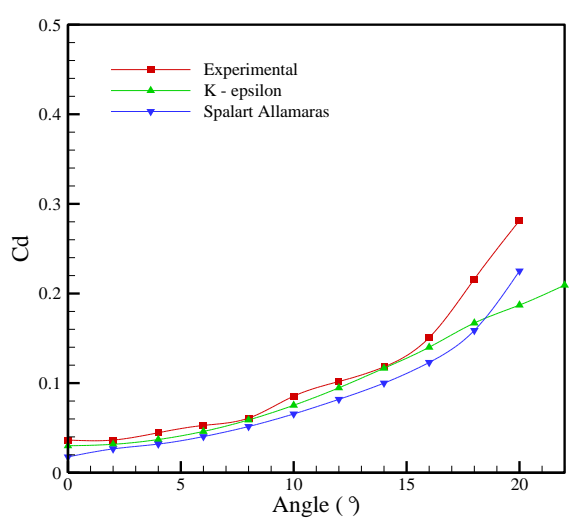

b) drag coefficient

Fig. 4. Experimental and numerical results.

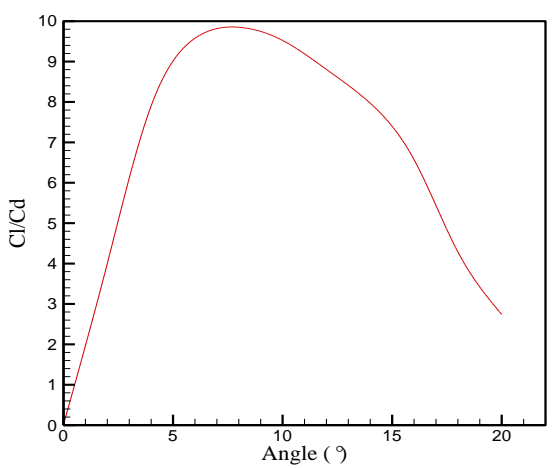

Fig. 5. Ratio of $C_{l} / C_{d}$ for various attack angle.

Distribution of turbulence and pressure around of NACA 0015 was shown in Fig. 6 from $2^{\circ}$ to $18^{\circ}$.

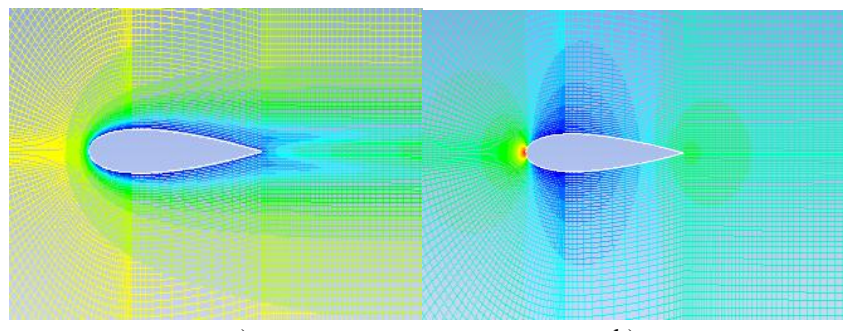

a)

b)

$0^{\circ}$ angle of attack

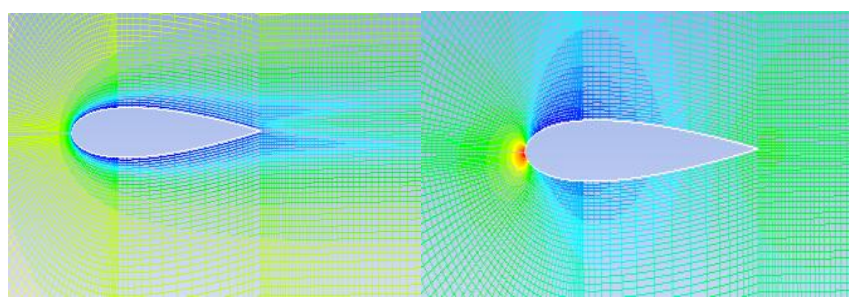

a)

b)

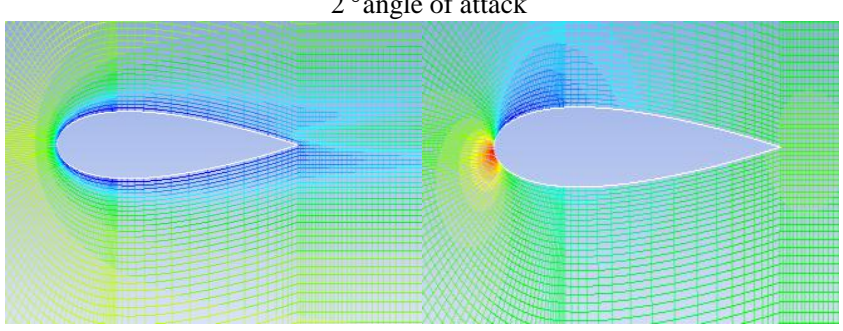

a)

$4^{\circ}$ angle of attack

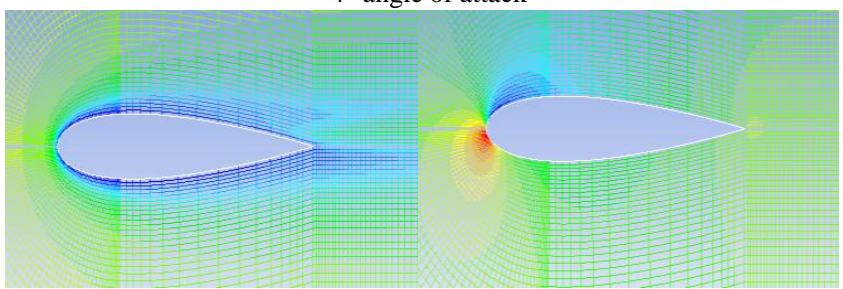

a)

$6^{\circ}$ angle of attack

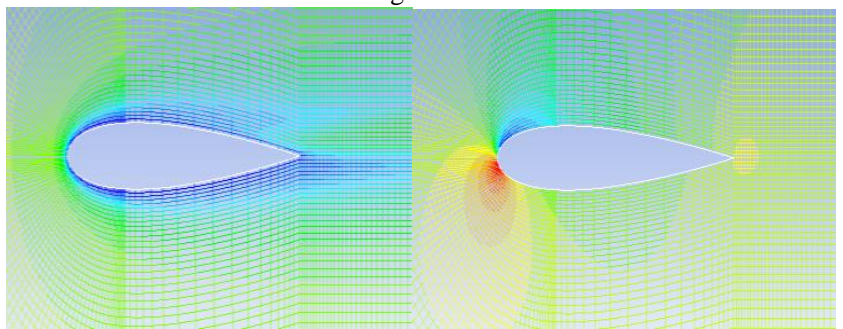

a)

b)

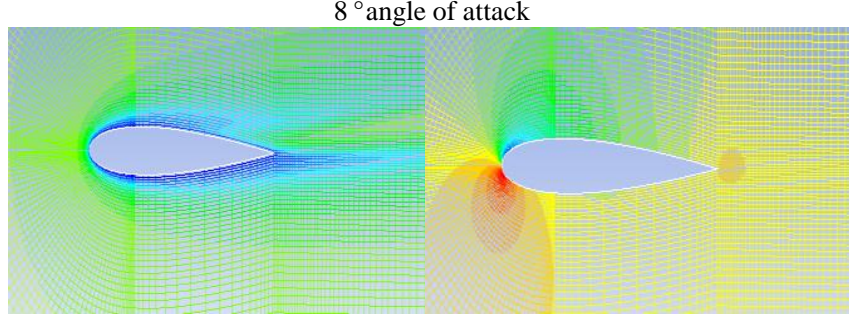

a)

b)

$10^{\circ}$ angle of attack

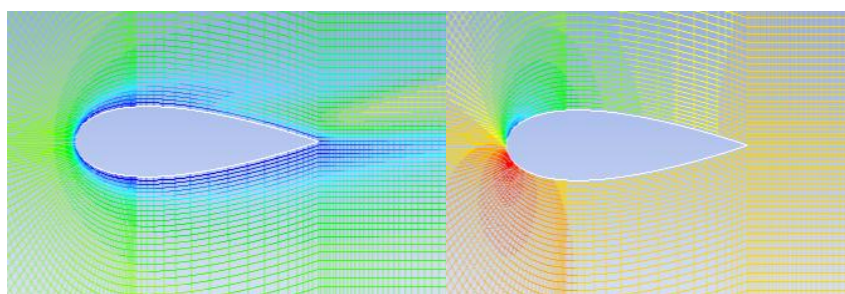

a)

b)

$12^{\circ}$ angle of attack

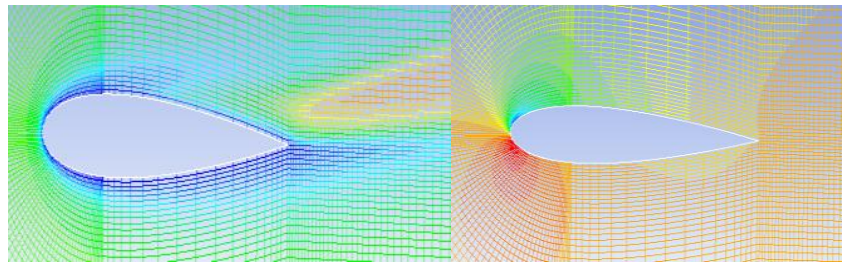

a)

b)

$14^{\circ}$ angle of attack 


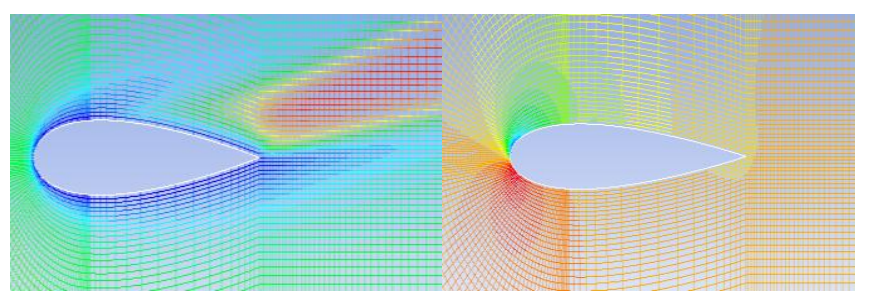

a)

b)

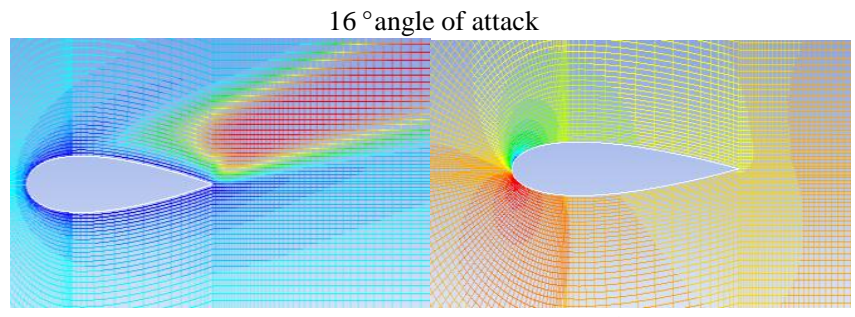

a)

b)

$18^{\circ}$ angle of attack

Fig. 6. a) Distribution of turbulence and b) Distribution of pressure.

The flow was laminar around the NACA 0015 airfoil between $0^{\circ}$ to $14^{\circ}$ angle of attack. Laminar flow was transition turbulence flow and pressure distribution changed around $16^{\circ}$ angle of attack so lift coefficient began decrease. It was shown in Fig. 6.

\section{CONCLUSIONS}

In this study lift and drag performances of NACA 0015 airfoil were performed. A FLUENT program was used to numerical calculations. Numerical and experimental results were compared. The calculation results were given as follows:

Drag and lift coefficients increased with increasing angle of attack.

Stall was started with $16^{\circ}$ attack angle. Lift coefficient decreased whereas; drag coefficient increased.

The optimum lift coefficient value was measured and computed at $16^{\circ}$

The optimum airfoil performance was measured and calculated at about $8^{\circ}$

Experimental and numerical analysis were shown a good results and similarity.

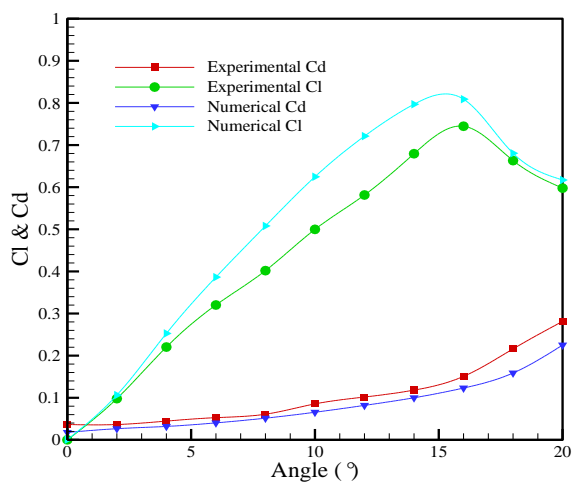

Fig. 7. Numerical and experimental lift and drag coefficient.

\section{ACKNOWLEDGEMENT}

The authors gratefully acknowledge the Faculty of Technology due to allowing to use wind tunnel. Experimental investigation has been conducted in this wind tunnel. Also the authors gratefully acknowledge University of Gazi owing to allowing to use CFD programs which is FLUENT.

\section{REFERENCES}

[1] S. S. Bhat and R. N. Govardhan, "Stall flutter of NACA 0012 airfoil at low Reynolds numbers," Journal of Fluids and Structures, vol. 41, pp. 166-174, May 2013.

[2] N. Benard, J. Jolibois, and E. Moreau, "Lift and drag performances of an axisymmetric airfoil controlled by plasma actuator," Journal of Electrostatic, vol. 67, pp. 113-139, January 2009.

[3] J. Yao, W. Yuan, J. Wang, J. Xie, H. Zhou, M. Peng, and Y. Sun, "Numerical simulation of aerodynamics performance for two dimensional wind turbine airfoils," Procedia Engineering, vol. 31, pp. 80-86, 2011

[4] L. B. Li, Y. W. Ma, and L. Liu, "Numerical simulation on aerodynamics performance of wind turbine airfoil," in Proc. World Automation Congress (WAC), 2012, pp. 1-4.

[5] F. Villalpanda, M. Reggio, and A. Ilinca, "Assessment of turbulence model for flow simulation around a wind turbine airfoil," Modeling and Simulation in Engineering, February 2011.

[6] H. C. Ravi, N. Madhukeshwara, and S. Kumarappa, "Numerical investigation of flow transition for NACA-4412 airfoil using computational fluid dynamics," International Journal of Innovative Research in Science Engineering and Technology, vol. 2, issue 7, pp. 2778-2785, July 2013.

[7] D. R. Troolin, E. K. Longmire, and W. T. Lai, "Timeresolved PIV analysis of flow over a NACA 0015 airfoil with Gurney flap," Experiments in Fluid, vol. 41, pp. 241-254, April 2006.

[8] W. L. Siauw, J.-P. Bonnet, J. Tensi, L. Cordier, B. R. Noack, and L. Cattafesta, " Transient Dynamics of the flow around a NACA 0015 airfoil using fluidic vortex generators," International Journal of Heat and Fluid Flow, vol. 31, pp. 450-459, 2010.

[9] G. R. Srinivasan, J. A. Ekaterinaris, and W. J. McCroskey, "Evaluation of turbulence model for unsteady flows of an oscillating airfoil," Computers \& Fluids, vol. 24, pp. 833-861, 1995

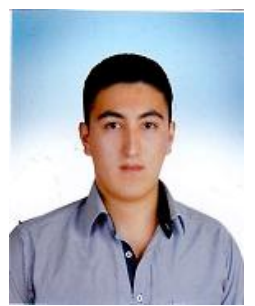

İzzet Şahin was born in Ankara. He graduated from the Mechanical Engineering Department at University of Kocaeli, Turkey in 2012. He has been working as a research assistance in the department of energy systems engineering at Gazi University. His main interests include thermodynamics, heat and mass transfer, computational fluid dynamics, renewable energy systems, fluid mechanics, numerical analysis.

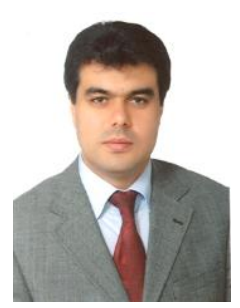

Adem Acır graduated from the Mechanical Engineering Department at the Gazi University, Turkey in 1997. He has been working as a full professor in the Department of Energy Systems Engineering at Gazi University. His main interests include thermodynamics, heat and mass transfer, analysis and modelling of energy systems, renewable energy systems, nuclear energy applications. 
